\title{
As trajetórias das professoras do Jalapão e seus percursos formativos
}

\author{
Odaléa Barbosa de Sousa Sarmento* \\ Jocyléia Santana dos Santos** \\ Daniela Patrícia Ado Maldonado***
}

Introdução

Os registros do processo histórico nas narrativas das professoras da

Mestre em Educação pela UFT. Especialista em Gestão Educacional e Metodologia do Ensino de Ciências Naturais - Matemática e Ciências; Especialista em Orientação Educacional; Especialista em Gestão da Educação Municipal. Graduada em Pedagogia pela Universidade Estadual do Tocantins (UNITINS). Gerente da Assessoria de Apoio aos Municípios (ASMET)/Seduc-TO; coordena o Plano Estadual de Educação do Estado do Tocantins e membro do Fórum Estadual de Educação (FEE). ORCID (Open Researcher and Contributor ID), disponível em: <https://orcid.org/0000-0002-19607035>. E-mail: professoraodalea@gmail.com.

** Pós- doutora pela Universidade Estadual da Amazônia (UEPA). Doutora e Mestre em História pela Universidade Federal de Pernambuco (UFPE). Graduação em História pela Pontifícia Universidade Católica de Goiás (PUC). Professora associada III da Universidade Federal do Tocantins (UFT), Coordenadora do Programa de Pós-Graduação em Educação (PPGE) da UFT). Coordena o Projeto Procad/Amazônia/CAPES-Programa de Cooperação Acadêmica com a Universidade do Estado do Pará (UEPA) e a Universidade Federal do Rio Grande do Norte (UFRN). ORCID (Open Researcher and Contributor ID), disponível em: <http://orcid.org/0000-0003-2335-121X>. E-mail: jocyleiasantana@gmail.com; jocyleia@uft.edu.br.

***Pós- Doutora pela Universidade Federal do Tocantins (UFT). Doutora em Educação pela Universidade Estadual Paulista Júlio de Mesquita Filho (UNESP). Mestre em Educação Especial (Educação do Indivíduo Especial) pela Universidade Federal de São Carlos (UFSCar). Psicóloga pela UFSCar. E-mail: ado_daniela@yahoo.com.br. 
educação infantil configuram a temática do estudo, entrelaça os fatos no contexto, à medida que os documentos retratam as características locais, da região do Jalapão. Esta é composta por cidades que se constituíram com a criação do Estado do Tocantins (1989), e outras constituídas a partir da migração dos povos oriundos, especialmente, da Bahia, do Maranhão e do Piauí, extremo leste do Tocantins.

A produção de mangabeiras dessa regiāo, cujo nome, em mapas antigos, era Chapada das Mangabeiras, foi um dos fatores predominantes para sua ocupação, principalmente no período d exploração de látex para borracha, na década de 40. Segundo Behr (2004, p. 34) começara depois dos índios, no século XVIII, cujos "vestígios" estão "nas inscriçoóes rupestres das cavernas da região". A pecuária, predominante até os dias de hoje, transformou, ao longo dos anos, fazendas em cidades pequenas que assim sobrevivem à contemporaneidade. $\mathrm{O}$ artesanato do capim-dourado e o turismo são as atividades econômicas crescentes no Jalapão, a Comunidade de Mumbuca (Mateiros) se destaca pela produção e pelo fornecimento de matéria prima às demais comunidades dessa região. Daqui circunstanciam o perfil dos sujeitos entrevistados, mulheres que ora protagonizam esta pesquisa.

Ao constituir o perfil das entrevistadas, o elemento identitário de gênero surge em meio aos dados levantados na pesquisa, validando que o atendimento à educação infantil, na região pesquisada, é predominantemente feminino. De abordagem qualitativa, as entrevistas semiestruturadas orientadas pela metodologia da história oral temática, possibilitaram que as professoras pudessem narrar suas trajetórias de formação, considerando-se seus contextos e suas similaridades da escolha profissional. Elas foram realizadas individualmente, consentidas e assinadas pelas participantes, gravadas em áudio e transcritas, orientadas especialmente com base em Meihy (2005) que categoriza a história oral e em Alberti (2004) quando aborda o tratamento da informação no uso da história oral.

Considerando sua relevância, a pesquisa dá voz às professoras e permite narrar as memórias das suas experiências ao longo do processo da escolarizaçáo, condição primordial do estudo, a partir do uso da metodologia da História Oral, pois a memória tem um caráter social. A História Oral, nesse campo dialógico ao qual se submete, faz da escuta um dos seus procedimentos mais valiosos, "lança a vida para dentro da própria história e isso alarga seu campo de ação” (Thompson, 1992, p. 44).

Desta forma, com base nos procedimentos metodológicos acima descritos, esta pesquisa promove a compreensão e a dimensão das fontes orais, advindas das entrevistas dos investigados. Ela, vale-se dessas fontes como forma de pensar a condição dos investigados enquanto sujeitos da contemporaneidade, considerando suas origens e percepçóes de vida. Segundo os autores Ferreira; Fernandes; Al- 
berti (2000, p. 79) “estes relatos transformam o passado em presente e a memória em realidade".

Cabe destacar algumas concepçóes acerca das narrativas como um dos elementos resultantes das transcriçôes das entrevistas com os sujeitos da pesquisa, as professoras. Esse momento estabelece relaçóes que perpassam o simples ato de entrevistar e transcrever os fatos narrados requer um olhar atento à temática da pesquisa. Tais trajetórias se enastram, na expectativa de responder ao objetivo geral da pesquisa, que é conhecer a formação das professoras que atuam na educação infantil na região do Jalapão no Tocantins. Sua escolarização e percursos foram levantados, visando identificar o perfil das professoras; fundamentar o processo formativo; relatar as escolhas profissionais.

As narrativas das professoras abordam aspectos do processo de escolarização como um dispositivo do saber que segundo Veiga (2002, p. 91) "se estabelece diante de elementos heterogêneos que envolvem os discursos, o espaço escolar, as ideias, o currículo" cujas relaçóes de poder se constituem como produtos desse saber. Nesse sentido, as narrativas colaboram para o entendimento das trajetórias de formaçáo que foram elementos norteadores para compreensão do processo formativo.

$\mathrm{Na}$ visão de Marcelo Garcia (1999), a formação inclui uma dimensão pessoal no desenvolvimento humano a qual é preciso priorizar frente a outras concepções eminentemente técnicas. Afinal, é através da informação que os sujeitos podem encontrar contextos de aprendizagem. Nesse sentido, as experiências narradas e evocadas nas entrevistas tencionaram questóes que permeiam esse percurso de formação inicial e continuada, consideradas as oportunidades de trabalho, carreira e formação que se consolidam como processo de constituição docente.

Nessa busca que os sujeitos se percebem como parte de um processo constitutivo de formação, objetiva-se compreender a sua atuação frente à docência na educação infantil, as concepções e escolhas que permeiam as relações dos processos de aprendizagem. No sentido amplo, a pesquisa engloba os conhecimentos, as competências, as habilidades (ou aptidóes) e as atitudes.

Para Freire (1991, p. 58), ninguém nasce educador ou marcado para ser educador, faz-se educador, formamo-nos como educadores permanentemente, na prática e na reflexão da prática. Essas concepçóes apresentadas provocam mudanças e se tornam fundamentais para a ampliação deste debate em torno da formação para os professores que, esta pesquisa se propóe a compreender.

\section{Formação de professores}


Para uma compreensão mais ampla do processo de formação de professores, retoma-se o contexto histórico quando a Lei Orgânica do Ensino Normal, aprovada em 1946, foi assinada logo após o fim da ditadura Vargas, quando houve uma certa uniformidade na formação para o magistério (Brasil, 1946). Mesmo com a primeira Lei de Diretrizes e Bases da Educação Nacional (LBD) de 1961 que dispóe sobre o ensino normal, Scheibe e Vale (2007) destacam que é o lugar de preparação dos professores do ensino obrigatório. Desde então, as mudanças ocorridas no que tange à formação de professores para o magistério ainda gera debates. Somente nos anos 80 é que, de fato, "houve uma progressiva remodelação do curso de pedagogia, nível superior, visando adequá-lo à preparação do professor para a educação infantil e aos anos iniciais do ensino fundamental" (Scheibe; Valle, 2007, p. 264).

A LDB de 1996 regulamenta que "A União, o Distrito Federal, os Estados e os Municípios, em regime de colaboração, deverão promover a formação inicial, a continuada e a capacitação dos profissionais de magistério" (Brasil, 1996, art. 62). ${ }^{1}$ Essa questáo coloca-se como desafiadora aos entes públicos, especialmente aos municípios, devido à responsabilização quanto à oferta da Educação Infantil, com "atendimento em creche e pré-escola às crianças de zero a cinco anos de idade" (Brasil, 2016).

Em relação aos processos formativos para a docência nas creches e pré-escolas nas Instituiçóes de Educação Infantil no Brasil, a formação continuada tem sido colocada em debate frente às questóes da atualidade e à construção do saber profissional que emergem da prática. Essa relação entre as instituiçôes formadoras e o contexto dos sujeitos que se formam, segundo Nóvoa (1986), "pressupóe a articulação entre o processo de formação, as instituiçóes onde se atua, os conhecimentos, as condiçóes para o exercício da docência e os diálogos da categoria com o Estado" (p. 22).

A formação inicial e continuada para os professores do ensino público, como direito, faz com que sua atuação de "mobilizador pela educação escolar" ponha em questáo que a "formaçáo inicial dos professores é crucial" para a transformação e "construção continuada da democracia e a luta pelos direitos humanos", sem deixar de lado "o papel relevante da formação continuada em suas vidas profissionais” (Gatti, 2013, p. 58-59).

Nesse sentido, dado os novos conceitos e transformaçóes que a Educação Infantil tem passado após a LDB de 1996, convém romper com paradigmas de

1 LDB - Nova redação nesse artigo 62, parágrafo 1º, incluída pela Lei no 12.056, de 2009.

2 Lei 13.306 de 2016 que altera o Estatuto da Criança e do Adolescente (1990). 
formação que contraste às novas exigências dos documentos e do contexto social contemporâneo. Reconhecendo a influência que esses paradigmas, que há séculos dominam os sistemas de ensino, têm sobre a formação dos professores, por conseguinte às práticas de inúmeros professores serão necessárias mudança. Para tanto, segundo Ferreira, Hammes e Amaral (2017, p. 65), é necessário buscar alternativas, pesquisar e investir na formação continuada que propicie e contribua com esse processo de transformação.

A Base Nacional Comum Curricular (BNCC) é um documento de caráter normativo que define o conjunto orgânico e progressivo de aprendizagens essenciais que todos os alunos devem desenvolver ao longo das etapas e modalidades da Educação Básica, de modo que tenham assegurados seus direitos de aprendizagem e desenvolvimento, em conformidade com o Plano Nacional de Educação (PNE). Esse documento normativo aplica-se exclusivamente à educação escolar, tal como a define o $\$ 1^{\circ}$ do Artigo $1^{\circ}$ da Lei de Diretrizes e Bases da Educação Nacional (LDB, Lei no 9.394/1996), e está orientado pelos princípios éticos, políticos e estéticos que visam à formação humana integral e à construção de uma sociedade justa, democrática e inclusiva, como fundamentado nas Diretrizes Curriculares Nacionais da Educação Básica (DCN). Há uma mescla não resolvida de concepçóes acerca do papel da Educação Infantil. Por um lado, destaca-se que a Educação Infantil deve estimular, facilitar e consolidar aprendizagens na infância como fase da vida, com ênfase em metas de aprendizagem e cuidados corporais, entendendo os direitos de aprendizagem como uma abstração introdutória de práticas dirigidas, as quais estão explicitadas adiante neste documento. Por outro lado, fala-se de organizar situaçóes e experiências que efetivem os direitos às apropriação, renovação e articulação de saberes e de conhecimentos, reconhecendo o potencial das crianças, valorizando o desenvolvimento integral e simultâneo dessas potencialidades, entendendo os seis direitos de aprendizagem (conviver, brincar, participar, explorar, expressar e conhecer-se) como formas de aprender no cotidiano, vivenciando desafios, solucionando problemas, desenvolvendo a afetividade em relação a outras crianças e adultos.

Cerisara (1999, p.16) compreende que "as instituiçóes de educação infantil têm uma especificidade que as toma diferentes da família e da escola e que devem, devido à especificidade da faixa etária de suas crianças, desenvolver atividades ligadas ao cuidado e à educação dessas crianças”.

Vincular as atividades pedagógicas a que se propóe o binômio cuidar e educar nas creches e pré-escolas, remete a discutir o perfil do professor que se forma. Conforme Azevedo (2013, p. 95), as propostas para a Educação Infantil têm revelado um perfil de professor que está em consonância com as várias tendências pedagógicas. Estas, por sua vez, caracterizam, ainda hoje, essa atividade têm influenciado na formação de professores que atuam nessa área. Nesse contexto 
de repensar a formação, Kishimoto (2004) defende que a qualidade da educação passaria, necessariamente, pela construção de uma prática coletiva, baseada em aprendizagens partilhadas.

\section{As professoras e suas trajetórias de formação}

As trajetórias das professoras pesquisadas encontram eco nas inquietações evocadas pelas mudanças do cenário educacional, pelas lutas de classe e pela introdução da Lei de Diretrizes e Bases da Educação que exigia a formaçáo em nível superior, Pedagogia, para o exercício da docência na década de 1995. Isto remete à pesquisa uma análise da formação das professoras, a partir de situaçóes de lugar, neste caso, do Jalapão; um adendo às narrativas colhidas. As fontes orais permitem diferentes interpretaçóes dos sujeitos, consideram suas singularidades e possibilitam rememorar as trajetórias destes, desvelando sentimentos ocultados ao longo da história.

Os sujeitos participantes da pesquisa são dez professoras que atuam na educação infantil; os critérios de seleção foram que atuassem, há mais de dois anos, em sala de aula da Educação Infantil na região do Jalapão e aceitassem participar da pesquisa. As participantes foram identificadas pelo sobrenome e ano de realização da entrevista, todas são oriundas da região do Jalapão, tem em média 43 anos de idade, com tempo de serviço variando entre dois e 27 anos.

Em relação à formação das professoras entrevistadas, os dados revelaram que $80 \%$ delas tem curso superior em educação, sendo três em Pedagogia, quatro em Normal Superior e um em Matemática. Dentre as entrevistadas, duas não possuem curso superior, das quais uma está em fase de conclusão do curso Pedagogia e uma apenas possui o magistério. A formação superior das professoras foi efetivada à distância, sinalizando que, mesmo diante das peculiaridades da regiáo do Jalapão, as professoras buscaram ampliar seus conhecimentos.

O espaço físico para realização das entrevistas "é prerrogativa do entrevistado" (Meihy; Holanda, 2017, p. 16). Desse modo, a maioria das professoras foi entrevistada no próprio local de trabalho, ou seja, nas unidades de ensino da educação infantil, em encontros previamente agendados, autorizados pelas secretarias de educação dos municípios pesquisados. O diário de campo foi um instrumento utilizado para relatar o caminho percorrido, desde os primeiros contatos até os sentimentos ali vivenciados durante a pesquisa e a realização das entrevistas. Para Meihy (2005, p. 187), o caderno de campo deve ser "[...] como um diário em que o roteiro prático seja anotado - quando foram feitos os contatos, quais os estágios para se chegar à pessoa entrevistada, como correu a gravação, eventuais incidentes 
de percurso.”.

As professoras entrevistadas aqui representam o perfil das mulheres do cerrado do Jalapão, que se destacam por miscigenarem características diversas, porém com origens locais; que têm uma vida simples, com vasta vivência e conhecimento do lugar onde residem.

\section{Narrativas do percurso formativo das professoras jalapoeiras}

As professoras, pois assim se identificam os sujeitos desta pesquisa, que dão vida e a sua vida narram com suas histórias orais, permitem serem ouvidas e sentidas. Permitem que se anotasse, observasse, transcrevesse, revisasse e que, por fim, apresentasse as vozes delas, que dão forma a esta pesquisa. Então:

Entender é isto: a gente vê uma coisa e vai procurando, na memória, um cabide onde a 'coisa' possa ser pendurada. Quando encontramos o cabide e a penduramos dizemos 'entendemos'. O fato do cabide já está lá na memória, à espera, significa que aquela ideia já estava prevista. Já era sabida. Não causava susto. A memória não tem cabide para coisas novas. (Alves, 2008, p. 17).

Em meio aos caminhos trilhados, a memória esteve presente nos relatos dessas mulheres professoras; além do que disseram nas entrevistas, os relatos por si só se manifestam. "Uma única voz descortina ambientes complexos, resistindo a esforços externos de compartimentalização" (Santhiago, 2009, p. 269, grifo nosso). Como reitera Portelli (2016, p. 91, grifo nosso) “a memória, como a própria narrativa também não é um texto fixo e um depósito de informações, mas sim um processo e uma performance" possibilita "ouvir essas vozes e suas histórias”.

Ao serem abordadas sobre formação, as professoras destacam o percurso formativo realizado nos municípios do Jalapão e regiáo, ofertado à distância pelas Universidades. Quando referenciam a formação continuada, apontam que esta nem sempre ocorrera. Maria das Mercedes Sousa de Castro, 45 anos (2018) diz que fez magistério em 1993, depois Normal Superior em 2003, "sou bacharel em Serviços Sociais, licenciatura em Fonética, sou pós-graduada em ensino infantil e séries iniciais", ainda acrescenta em relação à formação continuada, "não me lembro de uma formação da rede municipal".

Quanto ao percurso formativo, Marivone Alves destaca:

Nasci e me criei aqui [...] casei, tô seguindo minha vida e escolhi essa 
profissão [...] tenho 17 anos que eu trabalho. Eu me formei depois que comecei a trabalhar em 2001 e aí, em 2004 eu comecei o curso de pedagogia e terminei em 2007, aí quando estava com dois anos ai, eu fiz a pós. (Marivone Alves Lustosa, 2018).

$\mathrm{Na}$ fala da professora fica evidente o vínculo de suas vivencias com a região, o que reflete na formação.

Sobre o direito à formação, a LDB em seu artigo 61 "estabelece formação dos profissionais em educação de modo a atender às especificidades do exercício das atividades, bem como aos objetivos das diferentes etapas e modalidades da educação básica” (Brasil, 1996). No jalapão, esse direito foi desafiador para as professoras, pois essa região apresenta dificuldades de acesso e pouca infraestrutura de gestão pública nas diversas demandas: conduções, espaços formativos, serviços de atendimento. $\mathrm{O}$ acesso à educação remete ao passado, conforme Sobrinho (2018):

Estudei, e fiz o ensino fundamental e o ensino médio aqui mesmo na cidade, conclui o terceiro ano em 2000, não trabalhava na educação, trabalhava em outras áreas. [...] 2013, fiz a inscrição do Parfor. Eu, Aparecida Tavares Sobrinho [38 anos] fui contemplada, comecei a fazer o ensino superior na Universidade Federal do Tocantins - UFT, [...] fui da última turma de magistério do meu município [...] terminei o magistério em 2000. (Aparecida Tavares Sobrinho, 2018).

Observa-se que as falas de Lustosa e Sobrinho se detêm na formação inicial, nas oportunidades ofertadas pelo poder público. Um caso peculiar se evidencia quando Núbia Avelino da Silva (2018) relata: "sou professora do primeiro ano, licenciada em matemática”, a respeito de casos como esse de professores que não são das áreas de pedagogia e de normal superior ministrarem aula em Educação Infantil, Gatti (2018) comenta que muitos professores estão atuando em áreas para as quais não foram preparados.

As histórias se cruzam, evidenciando-se pelos aspectos culturais, interpretados nas falas de duas professoras: Raquel da Silva Evangelista (2017) "sou descendente de quilombola [...] a gente teve a oportunidade de fazer um curso aqui, música e arte, [...] agora na faculdade [...] faltam dois anos para mim terminar, eu já arrumei um emprego também, que foi lá na escola”. Essa professora vive na comunidade do Mumbuca, no Parque Estadual do Jalapáo, local onde se concentra a maior reserva da biodiversidade da regiáo, inclusive do Capim Dourado. Observa-se que o poder público contrata professores sem a formação mínima para atuaçáo 
na docência, pode-se justificar que essa prática decorre, provavelmente, da falta de profissionais qualificados na regiáo e das dificuldades de acesso ao município, nas estradas arenosas. Salviana Silva Rodrigues evidencia:

Nasci aqui, eu comecei a estudar nesta escola da comunidade, do pré a $4^{\mathrm{a}}$ série, era multisseriada. Comecei o magistério em Goiânia e terminei aqui, mas lá era chamado Normal, então tive que pagar disciplinas. [...] então a formação continuada foi o Progestão ${ }^{3}$, da Seduc [...] A pós-graduação foi em pedagogia. (Salviana Silva Rodrigues, 2018).

Ela carrega consigo a cultura do seu povo; embora tenha buscado alternativas de estudos em outros lugares, retornou à sua origem, onde vive e exerce a docência. As comunidades quilombolas, onde Evangelista (2017) e Rodrigues (2018) vivem, são dois contextos diferentes, mas com características sociais similares. Nas visitas a essas duas comunidades, constatou-se que a cultura predominante dos povos quilombolas é preservada, enraizada nas açóes da escola e presentes nos eventos escolares. A Comunidade Mumbuca vive da produção do artesanato do capim dourado, já a Comunidade de Barra da Aroeira, dos recursos da agricultura local e da assistência do governo. A escola é, para esse grupo, o seu maior patrimônio; seus integrantes zelam por ela e se impóem nas suas tomadas de decisôes. Esses registros foram ditos e percebidos no diálogo inicial para a realização das entrevistas e registrados no diário de campo.

A formação inicial e continuada aparece nas narrativas sobre o processo de escolarizaçáo, como se vê na fala de Antonia Ferreira Luz (2018) "Nasci aqui [...] só tenho o magistério, [...] comecei a estudar com 7 anos, [...] Naquele tempo ainda levava cadeira de casa pra sentar na escola, [...].”. E, em relação à formação continuada, manifesta-se: "participo de todas as formaçóes, PNAIC, ${ }^{4}$ Gestar". ${ }^{5}$

Fica evidenciada que a formação continuada é ofertada nesse local. Segundo Magalhães e Azevedo (2015, p. 33), a formação continuada é condição

3 PROGESTÃO é um programa de incentivo financeiro aos sistemas estaduais para aplicação exclusiva em açóes de fortalecimento institucional e de gerenciamento de recursos hídricos, mediante o alcance de metas definidas a partir da complexidade de gestão (tipologias A, B, C e D) escolhida pela unidade da federação.

4 PNAIC (Pacto Nacional pela Alfabetização na Idade Certa) é um curso de formação continuada que tem o propósito de apoiar todos os professores que atuam no ciclo de alfabetização, incluindo os que atuam nas turmas multisseriadas e multietapas, ofertados pelo Ministério da Educação (MEC) às redes que aderirem ao PNAIC e desenvolverem as açóes deste. (Brasil, 2018).

5 O Programa Gestão da Aprendizagem Escolar (GESTAR I) apresenta-se como um conjunto de açóes articuladas a serem desenvolvidas junto a professores habilitados para atuar da $1^{\mathrm{a}}$ à $4^{\mathrm{a}}$ séries ou do $2^{\mathrm{o}}$ ao $5^{\circ}$ anos do Ensino Fundamental, que estejam em exercício nas escolas públicas do Brasil (Brasil, 2018). 
necessária no processo de formação, mas não suficiente para o pleno exercício da docência garantida pela formação inicial de qualidade. Luz (2018) rememora os contextos de sua trajetória de formação, iniciada no ensino fundamental, caracterizando, em seu relato, as dificuldades de acesso à educação, demarcada pela ausência da formação superior.

No decorrer desses relatos, o processo de formação se desvela, o que permite referenciar as condiçóes e contextos das professoras Maciel e Ferreira (2018) na busca pela formação:

Eu iniciei com 7 anos na primeira série, como morava na fazenda [...] surgiu o Normal Superior, aí eu fiz, [...] fiz a pós-graduação. Mas quando eu já estava no curso de Normal Superior eu já estava sendo professora no município. Já participei de várias formações, mas para Educação Infantil nunca participei de nenhuma. (Rosimeire Andrade Maciel, 2018).

Já vou fazer 63 anos, é, comecei a minha carreira aqui [...] na época trabalhava na escola e não tinha luz, era muito difícil [...] quando você fazia o quarto ano, você já podia ir pra uma sala de aula, porque não tinha muitas opçóes, então foi por ai que comecei minha carreira. [...] fui pra Goiânia, fiz o magistério, mas tinha começado antes a fazer contabilidade, daí voltei pra cá, terminei o magistério, passei um bom tempo sem estudar. De repente surgiu a UNITINS aqui, em Aparecida do Rio Negro, aquela faculdade a distância, nós somos os primeiros alunos da Unitins aqui, fiz faculdade de Normal Superior. (Edilene de Sousa Ferreira, 2018).

As professoras carregam consigo a memória do seu percurso formativo, em que a escola rural nem sempre tinha as condiçôes mínimas para a oferta da educação. Dentre as peculiaridades, a escola "não tinha luz, era muito difícil" conforme destaca Edilene de Sousa. Ferreira (2018). Esse resgate do passado revela uma característica comum na regiáo, que com apenas a $4^{\mathrm{a}}$ serie podia se exercer a docência. Suas escolhas, em meio ao processo de constituição da profissão docente, não eram muitas. $\mathrm{Na}$ expressão da entrevistada "aquela faculdade à distância", embora não citada diretamente pelas outras entrevistadas, esta foi uma das poucas oportunidades de acesso ao ensino superior nesta região. Como não se sensibilizar com histórias tâo fortes que marcam a vida dessas professoras, assim como a da professora Reis (2018) ao narrar:

Estudei aqui mesmo, depois veio o curso de pedagogia a distância e eu me formei e, logo em seguida já fiz a pós-graduação nas séries iniciais. Para ter o magistério, fiz um curso Proformação, aí eu conclui [...] Para 
poder fazer a cada 15 dias e nas férias, todas as férias a gente ia né, levando colchão, a prefeitura ela pagava as nossas despesas, nós íamos eu e mais três professoras. Sempre participei de formação continuada. (Alexandrina Alves de Oliveira Reis, 2018).

Nos relatos dessa professora, destaca-se o percurso resiliente, cujos fatos passados, emaranhados na sua memória, perpassam os tempos. Relembrar o passado, a experiência de vida, a trajetória de formação e saberes adquiridos para o labor da docência permitiram, conforme afirmativa de Thompson (1992, p. 26), uma reconstrução mais realista e mais imparcial do passado, uma contestação ao relato tido como verdadeiro. Nessa busca por respostas, surge um registro resultante de um sujeito que se forma.

Meus pais eram analfabetos, minha mãe inclusive eu alfabetizei, ensinei ela né, depois de nós criados, eu já havia estudado, todos nós já estávamos criados. Eu a ajudei a aprender a fazer o nome, ela queria muito aprender a fazer o nome. (Alexandrina Alves de Oliveira Reis, 2018).

Fruto de sua formação, a professora, no seu relato, permite analisar o valor atribuído à leitura e à escrita, o desejo de ler e escrever. Embora não soubesse ler nem escrever, sua mãe ensinou aos filhos a importância desse saber.

Quanto à formação das professoras entrevistadas, segundo Gatti e Barreto (2009, p. 162), a própria escolarização de nível médio da mulher, formação para o magistério, é permeada pela representação do ofício docente como prorrogação das atividades maternas e pela naturalização da escolha feminina pela educação.

Outro fator presente já exposto nas caraterísticas das professoras, é que a maioria teve acesso ao ensino superior, por meio de curso a distância, uma vez que não há instituição ofertante nos municípios pesquisados. $\mathrm{O}$ ensino superior a distância foi regulamentado pela LDB no seu artigo $62, \S 3^{\circ}$, que dispóe "A formação inicial de profissionais de magistério dará preferência ao ensino presencial, subsidiariamente fazendo uso de recursos e tecnologias de educação a distância" (LDB, 1996, Incluído pela Lei no 12.056 , de 2009). As professoras que ora protagonizam as narrativas desta pesquisa retratam contextos que caracterizam a regiáo do Jalapão, cidades pacatas, de vidas simples que resistem ao tempo.

\section{Entre a escolha e a opção pela docência}

A discussão em torno da formação de professores tem se mostrado profí- 
cua nas dimensôes sociais em que ela se manifesta, possibilitando analisar suas implicações nas concepções teóricas e na atuação profissional. Os estudos em busca de interpretações que permitam a compreensão dos fatos narrados pelas professoras da Educação Infantil direcionam as impressôes iniciais deste registro.

Em meio às narrativas, para justificar os motivos da escolha para a profissão de professora e para a atuação na educação infantil, alguns relatos são convergentes: "[...] fiz magistério, quando foi na parte do estágio, me identifiquei, sempre gostei de crianças" (Aparecida Tavares Sobrinho, 2018); "prefiro ficar na educaçáo infantil, adoro trabalhar com criança, me sinto mãezona” (Núbia Avelino da Silva, 2018); acrescenta Alexandrina:

[...] sempre diziam: nós vamos levar ela para educação infantil [...] me identifiquei tanto [...] gosto da Educação Infantil [...] me identifico muito com as crianças, acho elas tâo verdadeiras! [...] 27 anos de trabalho na escola, [...] 6 anos na zona rural, com criança e lá era multisseriada. (Alexandrina Alves de Oliveira Reirs, 2018).

O que de fato comunga nesses relatos de Sobrinho, Silva e Reis (2018), o "gostar de crianças", teriam sido então as razóes de suas escolhas para se tornarem professoras. Retomando à fala de Silva (2018) ao expressar "adoro trabalhar com crianças, me sinto mãezona", configura-se uma dualidade da profissão, que para Arce (2001, p. 173) denota uma oscilação "entre o papel doméstico de mulher/ mãe e o trabalho de educar".

A escolha da profissão, do ponto de vista afetivo, tem uma relação subjetiva com as convivências que os sujeitos estabelecem, podendo serem incorporadas nas suas decisões. Essa incorporação é decisiva para a escolha profissional, pois o sujeito, conforme explica Primi (2000, p. 453), busca, em suas profissóes, algo que preencha suas expectativas tanto emocionais, quanto sociais. Esse sentimento de afeto pelas crianças como elemento motivador não é o principal argumento de escolha pela profissão na fala das demais professoras, pois, segundo Maria das Mercedes Sousa de Castro (2018) "o município não tinha professor formado e eu me identifiquei com eles, são muito carinhosos”. Para Rosimeire Andrade Maciel (2018) "quando consegui um emprego na prefeitura foi de Auxiliar de limpeza, [...] depois quando eu já estava no curso Normal Superior, já era professora”. Embora as professoras Castro e Maciel não explicitem, percebe-se que náo se trata de escolha, mas de oportunidade de trabalho.

Essa relação estabelecida entre a estabilidade no trabalho e as oportunidades destaca-se na fala de Raquel da Silva Evangelista (2017), quando expressa "Fiz faculdade $[. .$.$] arrumei emprego [...] é uma profissão que me descobri, [...] poder$ 
contribuir com a aprendizagem das crianças"; na convicção de Salviana Silva Rodrigues (2018) "Quando eu comecei a trabalhar [...] substituindo, no segundo ano do ensino fundamental, depois eu fui pra educação infantil. [...] Eu estou aqui até agora, 25 anos".

Afirmando essa relação de estabilidade versus oportunidade, Gatti (2010, p. 7), diz que "a escolha da docência como uma espécie de 'seguro desemprego', ou seja, como uma alternativa no caso de náo haver possibilidade de exercício de outra atividade”. Nesse sentido, Marivone Alves Lustosa argumenta:

[...] Eu entrei pra educação não por escolha, mas por falta de escolha, às vezes [...] não era aquele desejo a profissão, por falta de opção, [...] um dos melhores salários da educação na época, eu pensei é esse! [...] A profissão de um professor a gente aprende a amar, de acordo com o tempo, vai passando e a gente vai se apaixonando, corre nas veias depois, a educação. (Marivone Alves Lustosa, 2018).

Observa-se que Lustosa (2018) deixa claro que "por falta de escolha”, “opção", resume os motivos pela profissão docente, agregando a isso procura de oportunidade salarial, quando afirma: "um dos melhores salários". Ainda argumenta Edilene de Sousa Ferreira (2018) "a gente não escolhe, eu pelo menos não escolhi, foi questão da necessidade, [...] vontade de ter as coisas, oportunidade”. E por fim, que a profissão de professor "aprende a amar", assim se dão as preferências.

Mas há evidências de que os motivos de escolha vêm da convivência, das interaçôes estabelecidas no período estudantil na infância e na família, como no caso da professora, Antonia Ferreira Luz (2018): "Naquela época, [...] do tempo da composição [...] toda vez que ia fazer composição, qual seu ideal, eu queria ser professora. [...] Eu era mais nova e tinha mais paciência, mais ainda gosto de criança, [...] não me vejo fora da sala de aula.”. Ao rememorar seu percurso de formação desde a infância, Antonia Ferreira Luz (2018) "queria ser professora", desde criança. Quando ela se refere à composição, "do tempo da composição" é uma palavra utilizada, segundo a professora, "quando os alunos faziam texto de cunho próprio". No dicionário Michaelis (2018), a expressão "composição", dentre as diversas interpretaçóes, se refere à ação de compor.

A especificidade das escolhas para a docência pode ser entendida como "o conjunto de comportamentos, conhecimentos, destrezas, atitudes e valores que constituem a especificidade de ser professor" (Sacristán apud Nóvoa, 1995, p. 64), na busca pela afirmação na carreira docente. Esses relatos, nas vozes das professoras, traduzem experiências singulares, uma história comum enquanto sujeitos que compartilham elementos constituintes de suas formaçóes. Como uma formação fragmentada em meio às oportunidades que surgiam, em cursos a distância, na 
maioria das vezes, conciliando o trabalho, o estudo e a vida familiar. $\mathrm{O}$ processo de busca pela formação para atuar na docência de educação infantil perpassa pelo reinventar-se enquanto sujeitos sociais do cerrado jalapoeiro.

Considerando os caminhos trilhados, a metodologia adotada permitiu elucidar os sentimentos de pertencimento, resultando numa relação harmoniosa das falas que ecoaram juntas na pesquisa, unindo o belo Jalapão aos contextos de formação a que foram submetidas as professoras de educação infantil.

\section{Considerações finais}

As professoras foram se tornando conhecidas ao longo das análises dos relatos, todas oriundas da região do Jalapão, tiveram suas vidas constituídas ali mesmo, familiar e profissional. Em relação à formação, as professoras iniciaram a prática profissional muito cedo, algumas delas apenas com a $4^{\mathrm{a}}$ série, como descrito por Ferreira (2018), outras após o magistério. A maioria cursou Licenciatura e teve seu ingresso no Ensino Superior quando já exercia o magistério. Observa-se também que os cursos superiores foram realizados após a LDB. Isto confirma a exigência disposta na Lei e Atos Normativos subsequentes, levando as professoras a aproveitarem as oportunidades que lhes eram acessíveis na região, em que a maioria estudou ensino superior à distância. A formação continuada é quase inexistente, as professoras não a possuem, e onde ela já aconteceu, é descontínua, pois ocorrera uma única vez. A compreensão das "escolhas" para atuar na Educação Infantil foi revelada tanto no estágio, por gostarem de crianças, quanto pela oportunidade de trabalho, conciliando os afazeres docentes e a família.

Portanto, as questóes levantadas quanto ao que preconiza a legislação e, de fato, como ocorre, na mais remota das condiçóes em que os sujeitos se encontram, mostra que ainda há muitas histórias a serem narradas a fim de assegurar a qualidade desejada para a formação de professores de Educação Infantil. Dentre o que se propõe: formação continuada, com foco nas concepções de cuidar e educar crianças da creche e da pré-escola; estudo dos documentos que orientam o planejamento articulado às rotinas de sala de aula; possibilidade de intercâmbios de formação com foco nas culturas quilombolas das comunidades referenciadas (Aroeira, em Santa Tereza e Mumbuca, em Mateiros), as quais, relacionadas às concepções da BNCC, podem trazer importantes contribuiçôes ao currículo sobre as diversidades étnicas, culturais e sociais dos povos brasileiros.

Percebe-se que a opção de escolha para exercício do magistério nem sempre ocorrera de forma vocacional, mas por oportunidade de emprego e como uma forma de permanência do local de residência. As narrativas das professoras de Educação 
Infantil do Jalapão, contadas e recontadas com a placidez que a pesquisa lhes colocou, como a condição de oportunidades muitas vezes negadas, foi o meio das professoras serem ouvidas e conhecidas. Agora, de posse dessas histórias, experiências e relatos, nos quais as professoras evidenciaram com lucidez suas origens e seus sonhos vividos na regiáo do Jalapão, tornam-se importantes indicaçóes para futuras pesquisas. Por exemplo, contribuiçôes relevantes para a história da regiáo do Jalapão, considerando os contextos de aprendizagens advindas das interaçóes e de práticas de formação que sugerem um olhar mais atento por parte das instituiçóes ofertantes, das políticas de gestão educacional e de interesses científicos.

\section{Referências}

ABRAMOWICZ, Anete; TEBET, Gabriela Guarnieri de Campos. Educação Infantil: um balanço a partir do campo das diferenças. 2016. Disponível em: $<$ hwww.scielo.br > pdf > pp > v28s1 , 0103-7307-pp-28-s1-0182>. Acesso em: 11 out. 2018.

ALBERTI, Verena. Ouvir contar: textos em história oral. Rio de Janeiro: Editora FGV, 2004.

ALVES, Rubem. O Melhor de Rubem Alves. Curitiba: Editora Nossa Cultura, 2008.

ARCE, Alessandra. Documentação oficial e o mito da educadora nata na educação infantil. Cadernos de Pesquisa, São Paulo, n. 113, p. 167-184, 2001.

AZEVEDO, Heloisa Helena Oliveira de. Educação Infantil e formação de professores: para além da separação cuidar e educar. São Paulo: UNESP, 2013.

BEHR, Miguel Von. Jalapão: Sertão das águas. São Jose dos Campos, SP: Somos Editora, 2004.

BRASIL. Constituição dos Estados Unidos do Brasil (1946). Diário Oficial [da] República Federativa do Brasil, Rio de Janeiro, 19 set. 1946. Disponível em: $<$ http://www.planalto.gov.br/ccivil_03/Constituicao/Constituicao46.htm>. Acesso em: 28 out. 2018. 
BRASIL. Lei no 13.478, de 30 de agosto de 2017. Altera a Lei no 9.394, de 20 de dezembro de 1996 (Lei de Diretrizes e Bases da Educação Nacional), para estabelecer direito de acesso aos profissionais do magistério a cursos de formação de professores, por meio de processo seletivo diferenciado. Diário Oficial [da] República Federativa do Brasil. Brasília, DF, 31 ago. 2017, seção 1, p. 2. Disponível em: <www.planalto.gov.br>. Acesso em: 16 mar. 2017.

BRASIL. Ministério da Educação. Secretaria da Educação Básica. Base Nacional Comum Curricular. Brasília, 2017, DF. Disponível em: <http://basenacionalcomum.mec.gov.br/abase>. Acesso: 12 jul. 2018.

CERISARA, Ana Beatriz. Educar e cuidar: por onde anda a educação infantil? Perspectiva, Florianópolis, v. 17, n. especial, p. 11-24 jul./dez. 1999. Disponível em: <https://periodicos.ufsc.br/index.php/perspectiva/article/viewFile/10539/10082>. Acesso em: 10 out. 2018.

FERREIRA, Marieta. Moraes; FERNANDES, Tânia Maria; ALBERTI, Verena (Org.). História oral: desafios para o século XXI. Rio de Janeiro: Editora Fiocruz; Casa de Oswaldo Cruz; CPDOC - Fundação Getúlio Vargas, 2000.

FERREIRA, Franchys Marizethe Nascimento Santana; HAMMES, Care Cristina; AMARAL, Kelly Cebelia das Chagas do. Interdisciplinaridade na formação de professores: rompendo paradigmas. Revista Diálogos Interdisciplinares - GEPFIP, Aquidauana, v. 1, n. 4, p. 62-76, dez. 2017.

FREIRE, Paulo. A Educação na Cidade. São Paulo: Cortez, 1991.

GATTI, Bernadete Angelina; BARRETTO, Elba Siqueira de Sá ( Org.). Professores do Brasil: impasses e desafios. Brasília, DF: UNESCO, 2009. 264 p. Disponível em: <http://unesdoc.unesco.org/images/0018/001846/184682por.pdf>. Acesso em: 04 nov. 2018.

GATTI, Bernadete Angelina. Educação, escola e formação de professores: políticas e impasses. Educar em Revista, Curitiba, n. 50, p. 51-67, out./dez. 2013.

GATTI, Bernadete Angelina. Formação de professores no Brasil: características e problemas. Educ. Soc., Campinas, v. 31, n. 113, p. 1355-1379, out./dez. 2010. Disponível em: <http:/www.scielo.br/pdf/es/v31n113/16.pdf>. Acesso em: 12 mai. 2018. 
KISHIMOTO, Tizuko Morchida. O sentido da profissionalidade para o educador da infância. In: BARBOSA, R. L. L. (Org.). Trajetórias e perspectivas da formação de educadores. São Paulo: Editora UNESP, 2004.

MAGALHÁES, Ligia Karam Corrêa de; AZEVEDO, Leny Cristina Soares Souza. Formação Continuada e suas implicaçóes: entre a Lei e o trabalho docente. Cad. Cedes, Campinas, v. 35, n. 95, p. 15-36, jan./abr. 2015. Disponível em: <http:// www.scielo.br/pdf/ccedes/v35n95/0101-3262-ccedes-35-95-00015.pdf.>. Acesso em: 4 nov. 2018.

MARCELO GARCIA, Carlos. Formação de professores. Para uma mudança educativa. Porto: Porto Editora, 1999.

MEIHY, José Carlos Sebe Bom. Manual de história oral. 5 ed. São Paulo: Edições Loyola, 2005.

; HOLANDA, Fabíola. História oral: como fazer, como pensar. 2. ed. São Paulo: Contexto, 2017.

NÓVOA, Antonio. Do mestre-escola ao professor do ensino primário. Subsídios para a história da profissão docente em Portugal (séculos XVI-XX). Lisboa: ISEF, 1986.

PORTELLI, Alessandro. História Oral como Arte da Escuta. São Paulo: Letra e Voz, 2016.

PRIMI, Ricardo; MUNHOZ, Alícia Maria Hernanez; BIGHETTI, Cássia Aparecida; NUCCI, Eliane Porto Di.; PELLEGRINI, Maria Carolina Kussama; MOGGI, Melissa Aparecida. Desenvolvimento de um Inventário de Levantamento das Dificuldades da Decisão Profissional. Psicologia: Reflexão e Crítica, v. 13, n. 3, p. 451-463, 2000.

SANTOS, Mariana dos; TAVARES, Diego; FREITAS, Denise (Org.). A escolha da profissão professor - Uma história envolvendo o passado. Encontro Nacional de Pesquisa em Educação em Ciências - ENPEC, 9, Águas de Lindóia, SP. Atas... Águas de Lindóia, 2013.

SACRISTÁN, José Gimeno. Consciência e ação sobre a prática como libertação profissional dos professores. In: NÓVOA, Antonio. (Org.). Profissáo professor. Porto: Editora Porto, 1995. 
SANTHIAGO, Ricardo. Solistas dissonantes: história (oral) de cantoras negras. São Paulo: Letra e Voz, 2009.

SCHEIBE, Leda; VALLE, Ione Ribeiro. A formação dos professores no Brasil e em Santa Catarina: do normalista ao diplomado na educação superior. In: NASCIMENTO, Antônio dias. HETKOWSKI, Tânia Maria (Org.). Memória e formação de professores [online]. Salvador: EDUFBA, 2007. 310 p. Disponível em: $<$ http://books.scielo.org>. Acesso em: 4 out. 2018.

THOMPSON, Paul. A voz do passado: história oral. 2. ed. Trad. Lólio Lourenço de Oliveira. Rio de Janeiro: Paz e Terra, 1992.

VEIGA, Cynthia Greive. A Escolarização como projeto de civilização. Rev. Bras. Educ. [online] 2002, n. 21, p. 90-103. ISSN 1413-2478. Disponível em: <http:// www.scielo.br/pdf/rbedu/n21/n21a07>. Acesso em: 18 dez. 2019.

\section{Fontes orais}

CASTRO, Maria das Mercedes Sousa de [45 anos]. [jun. 2018]. Entrevistador: Odaléa Barbosa de Sousa Sarmento. Santa Tereza, TO, 8 jun. 2018.

EVANGELISTA, Raquel da Silva [24 anos]. [nov. 2017]. Entrevistador: Odaléa Barbosa de Sousa Sarmento. Mateiros, TO, 15 nov. 2017.

FERREIRA, Edilene de Sousa [62 anos]. [abr. 2018]. Entrevistador: Odaléa Barbosa de Sousa Sarmento. Aparecida do Rio Negro, TO, 13 abr. 2018.

LUSTOSA, Marivone Alves [39 anos]. [abr. 2018]. Entrevistador: Odaléa Barbosa de Sousa Sarmento. Novo Acordo, TO, 13 abr. 2018.

LUZ, Antonia Ferreira [51 anos]. [abr. 2018]. Entrevistador: Odaléa Barbosa de Sousa Sarmento. Aparecida do Rio Negro, TO, 13 abr. 2018.

MACIEL, Rosimeire Andrade [50 anos]. [abr. 2018]. Entrevistador: Odaléa Barbosa de Sousa Sarmento. Aparecida do Rio Negro, TO, 13 abr. 2018.

REIS, Alexandrina Alves de Oliveira [47 anos]. [abr. 2018]. Entrevistador: Odaléa Barbosa de Sousa Sarmento. Aparecida do Rio Negro, TO, 13 abr. 2018. 
RODRIGUES, Salviana Silva [51 anos]. [jun. 2018]. Entrevistador: Daniela Patrícia Ado Maldonado. Santa Tereza, TO, 8 jun. 2018.

SILVA, Núbia Avelino da [30 anos]. [jun. 2018]. Entrevistador: Daniela Patrícia Ado Maldonado. Ponte Alta, TO, 8 jun. 2018.

SOBRINHO, Aparecida Tavares [38 anos]. [abr. 2018]. Entrevistador: Odaléa Barbosa de Sousa Sarmento. Novo Acordo, TO, 13 abr. 2018.

Resumo: $\mathrm{O}$ artigo objetiva narrar trajetórias de formação de professoras da educação infantil do Jalapão, região de cerrado, localizado a leste do estado do Tocantins. A partir da metodologia da história oral temática, foram realizadas entrevistas semiestruturadas com 10 professora. A base teórica fundamentou-se em autores como Freire (1991); Nóvoa (1986); Garcia (1999); por abordarem concepçôes de formação e em Scheibe e Vale (2007); Gatti (2013) para a análise das concepções de formação de professores no contexto atual. Quanto aos aportes legais, foram analisadas as garantias de formação de professores, Brasil (1996; 2016), considerando diferentes concepçôes de interpretaçôes de seus artigos e análises na aplicabilidade da educação infantil. A pesquisa foi realizada de maio a agosto de 2018. Utilizou-se a História Oral com os autores Alberti e Sebe Meihy. As professoras destacaram que os programas disponibilizados pelo governo federal em parceria com o estado, PNAIC e Gestar, não são contínuos e não há capacitação para a educação infantil. A relaçáo que se estabelece entre a formação adquirida e as práticas pedagógicas é divergente. Portanto, não conseguem estabelecer articulação entre os saberes cotidianos, a prática e a teoria. Percebe-se uma lacuna na formação dessas professoras para a educação infantil.

Palavras-chave: Formação de professoras. Educação Infantil. História Oral. Jalapão.

\section{The paths of Jalapáo's teachers and their formative histories.}

Abstract: The paper aims to narrate the formative path of teachers of early childhood education in Jalapão, Cerrado region, located to the east of the state of Tocantins (Brazil). Based on the thematic oral history methodology, semi-structured interviews were conducted with 10 teachers. The theoretical fundamentals were based on authors such as Freire (1991); Nóvoa (1986); Garcia (1999) for approaching conceptions of formation, and on Scheibe and Vale (2007); Gatti (2013) concerning the authors' conceptions of teacher education in the current context. Regarding the legal contributions, we analyzed the guarantees of teacher education, Brazil (1996; 2016), considering different interpretation conceptions 
from their papers and studies on the applicability of early childhood education. The research was conducted from May to August 2018. Oral History was used with authors Alberti and Sebe Meihy. The teachers pointed out that the programs offered by the federal government in partnership with the state, PNAIC and Gestar, are not continuous; and there is no training for early childhood education. The relationship established between the acquired formation and the pedagogical practices is divergent. Therefore, they fail to establish articulation between everyday knowledge, practice and theory. There is a gap in the training of these teachers for early childhood education.

Keywords: Teacher training. Child education. Oral History. Jalapão.

Recebido em 21/08/19

Aprovado em 31/10/19 